Revista Aspas

ppgac - USP

Apresentação do Tema

\title{
POLÍTICAS PÚBLICAS E ARTES CÊNICAS: RELAÇÕES ENTRE PRODUÇÃO, MERCADO E
} ESTADO

PUBLIC POLICIES AND PERFORMING ARTS: RELATIONS BETWEEN PRODUCTION, MARKET AND STATE

POLÍTICAS PÚBLICASY ARTES ESCÉNICAS: RELACIONES ENTRE PRODUCCIÓN, MERCADO Y ESTADO

Laura Haddad

Laura Haddad

Atriz, diretora e produtora cultural. Formada em Direito pela PUCPR,

Especialista em Gestão e Políticas Culturais pela Universidade de Girona - Espanha, Doutoranda e Mestre em Artes Cênicas pela USP.

E-mail: laurahaddad@usp.br. 


\section{Universidade de São Paulo - inverno pandêmico de 2021.}

Nesta edição da Revista Aspas, lançada após um longo e caótico período pandêmico que, infelizmente, ainda vivemos, pudemos perceber o quanto este tema nunca se fez tão oportuno. Em um claro desmonte e sucateamento da cultura em nosso país, com o atual governo enxergando artistas como inimigos, a escassez de produções com teatros e espaços culturais públicos ou privados fechados ou em lenta retomada, buscamos refletir sobre os desafios que o artista, o produtor cultural ou gestor de cultura enfrenta diante de um novo sistema de produção cultural no Brasil que tem a tecnologia, a virtualização e o autoempreendedorismo - com as novas plataformas digitais de distribuição e uma automação da produção da arte como elementos importantes para a constituição de uma nova forma de fruirmos um bem cultural.

No Brasil, as políticas públicas de cultura estão reduzidas, desde muito, a uma política de editais o que inviabiliza uma reflexão mais assertiva acerca de outras possibilidades mais condizentes de pensar e agir na Cultura, como o que acontece em outros países mais desenvolvidos. Depois da criação do Ministério da Cultura em 1985 e da institucionalização de secretarias e fundações estaduais de cultura, as discussões sobre políticas públicas e gestão cultural começaram a tomar corpo, mas muito pouco se fez além da criação de editais públicos ou privados, de renúncia fiscal ou fundo.

Aqui, é interessante abrir um parágrafo para observar uma maior oferta de editais de fundos de cultura no governo de Luiz Inácio Lula da Silva ${ }^{1}$ e Dilma Roussef ${ }^{2}$ e o impacto que isto teve na produção de conteúdos artísticos direcionados para determinados grupos demográficos que, até então, estavam esquecidos pelo - agora extinto - Ministério da Cultura.

A não participação da iniciativa privada como incentivadora dos projetos nestes editais, proporcionou uma democratização do acesso inédita no país, uma vez que nos fundos de cultura há o aporte direto de verba pelo

\footnotetext{
1 Presidente da República durante o período de 01 de janeiro de 2003 a 01 de janeiro de 2011.

${ }^{2}$ Presidente da República durante o período de 01 de janeiro de 2011 a 31 de agosto de 2016.
} 
poder público. E assim, em um nível mais geral, os públicos de certas categorias de idade / renda / educação foram mais valorizados do que outros, em grande parte, com base na suposição de que estes públicos são mais propensos a responder em curto e médio prazo às demandas de formação e difusão de produtos culturais e também desenvolver uma demanda latente ou, dependendo dos casos, uma demanda ocasional reativa, como classifica de forma muito interessante o Manual Atalaya de Gestión Cultural. ${ }^{3}$

Paralelamente, houve uma crescente proliferação de cooperativas, redes e coletivos de artistas e produtores culturais, incentivados pela ampliação dos mecanismos de apoio e financiamento à cultura, tanto no setor público quanto privado. Estes grupos, a cada dia e cada vez mais, entendem a importância da sua arte e a necessidade de um sistema de produção eficiente visando atender todas as etapas desta produção de uma maneira mais eficaz.

Ao refletirmos acerca dos primeiros marcos para a constituição desta área como profissão, somos levados à compreensão de que ainda falta muito estudo e pesquisa na área da cultura no Brasil, especificamente na área de produção e gestão cultural onde a cena artística neste aspecto é muito tímida, praticamente anônima.

A partir da segunda metade do século $\mathrm{XX}$, as políticas culturais têm adquirido relevância na agenda internacional, tornando-se alvo de investigações em distintas áreas. Porém, ainda existem poucos estudos sobre a temática que priorizem a reflexão teórica e conceitual. Diante desta constatação, há uma crescente necessidade da propositura de debates das políticas públicas de cultura não só no âmbito latinoamericano, mas também em cada Estado brasileiro, com suas especificidades, demandas e dinâmicas de produção, numa abordagem crítica e também de cunho prático, de aplicação e resultados. Pressupõe-se que, ao aprofundar estas questões, haja um importante passo em busca de uma delimitação operacional e, ao mesmo tempo, crítica das políticas culturais, para que estas possam de fato, extrapolarem o limite perigoso de uma reduzida e atrasada política de editais.

\footnotetext{
${ }^{3}$ Manual de Gestión Cultural disponível em http://atalayagestioncultural.es/. Acesso em 14/07/2021.
} 
Muito dos estudos aprofundados sobre política públicas, geralmente estão vinculadas a disciplinas específicas de Administração ou Economia. Isso pode levar a uma falha em avaliar as diferenças reais no campo da cultura em termos do que estão de fato investigando, de como realizam essas investigações e o mais importante: de como aplicam. As diferenças que existem nos níveis ontológico, epistemológico e metodológico entre diferentes meios e modos de se pensar políticas públicas para a área cultural, significam que não é possível simplesmente adotar o que rege uma cartilha préestabelecida sobre política cultural pelo seu valor nominal.

Sem uma maior compreensão teórica e metodológica das ferramentas disponíveis para a análise da política cultural do local, do que está ao nosso entorno, é improvável que uma abordagem mais sofisticada de análise seja gerada.

Pode parecer mais fácil entender as políticas públicas de cultura e o apoio do governo para a preservação do patrimônio por exemplo, mas quando falamos das artes cênicas, este entendimento se torna muito mais difícil. $E$ com o advento da pandemia da COVID19 e um processo - sem volta - de uma virtualização da cultura e da fruição de arte pelas multiplataformas, a intervenção governamental parece perder sentido e ser menos relevante. Parece. Mas a realidade mostra-se outra. Com a Lei Aldir Blanc promulgada em 2020 para subsidiar artistas na pandemia, vieram à tona as especificidades do setor e como os parcos investimentos, sejam eles públicos ou privados, mais ou menos direcionados, levam a diferentes cenários e realidades culturais.

Não há como negar que todo o julgamento sobre a qualidade e a importância de uma criação artística é delegado a poucos interessados, de fato, em uma execução producente de uma política cultural e a um quase completo desconhecimento da produção que orbita de forma independente. Com a extinção do Ministério da Cultura em 2019 e de Secretarias específicas de Cultura em diversos Estados brasileiros, os gestores públicos procuram, desesperadamente, concentrar-se na formulação de um projeto missionário para uma nova política cultural que tem na pluralidade seu maior desafio. Mais do que isso: precisam certificar-se de que a mesma será implantada de forma 
adequada, garantindo o acesso de um maior número possível de beneficiários e beneficiárias.

Paralelamente, chovem críticas abundantes sobre o mercado que incentiva uma cultura orientada para o dinheiro e a forma empobrecida de como as pessoas podem criar e produzir com menos. Para além dessa crítica, teme-se um mundo onde as pessoas, os artistas, sua arte e suas organizações culturais sejam tratadas apenas como compradores ou vendedores de bens e serviços. Valem as demandas do mercado, da empresa que incentiva, do conteúdo on demand, do poder de compra, não o contexto histórico, a arte-educação ou a livre criação sem amarras. Quem paga, participa. As forças do mercado emburrecem expressões de alta cultura para chamar a atenção das massas. A cultura, portanto, torna-se parte do entretenimento, de uma indústria. Há neste perigoso território, uma nítida preferência de que a cultura se expresse em espaços assépticos e de uma estética refinada para um público de elite que, por sua vez, faz um esforço para entender do que se trata.

Espaços culturais privados de bancos ou de Organizações Sociais (OS), considerados democráticos, intimidam públicos que, ao se depararem com estes espaços de edificações modernas e deslumbrantes aos olhos de quem passa, sentem-se na maioria das vezes, "indignos" para frequentar estes lugares. Sim, a arte não é para todos.

O Estado tem usado a economia para entender a política cultural, e isso é considerado filisteu. Secretários de Cultura estaduais e/ou municipais são tratados com desprezo, a menos que tragam mais dinheiro para a pasta e nenhuma opinião sobre cultura ou política cultural. A Cultura, é a prima pobre, a pasta que sobra, que ninguém quer porque não tem status algum e que não serve para nada. Na maioria das vezes, é dada como "presente" para apoiadores e partidos políticos alinhados ao atual governo, alocando "gestores e gestoras" que não são da área e que possuem zero intimidade com o tema. Tem-se aí a origem de um grande problema. Os profissionais, gestores de cultura com formação na área, artistas - e não políticos! - são os que devem decidir quais as melhores políticas para o setor.

Sabemos também, que não se pode deixar a cultura aos caprichos do 
mercado. Há de se considerar que a cultura é uma boa experiência que leva tempo para ser vivenciada, apreciada e tem fortes externalidades sociais. É intragável, portanto, se apenas a elite cultural gostar de cultura, porque a cultura é como a linguagem em essência, um fenômeno social. Se ela não pode ser excluída, ela é um bem público. As políticas públicas devem entendêla como um valor social, mas também como valor de existência, valor de opção regional e intergeracional. E nenhum desses fatores é internalizado pelo mercado.

O desafio para a maioria dos formuladores de políticas no setor é impulsionar a alta cultura, incluindo as sinergias com baixa cultura. Se esforçam por uma democracia cultural, certificando-se de que mais pessoas tenham a competência para apreciar e compreender as mais diversas expressões artísticas. A democracia da cultura não está preocupada com emburrecimento da alta cultura, mas como tornar a alta cultura disponível e acessível a novas e mais pessoas. Isso realça o caráter de bem público da cultura. Além disso, expressões artísticas culturais só se tornam significativas se forem confrontadas com um público crítico. Além disso, a cultura tem de competir com muitas outras atividades de lazer, o que explica, em parte, as salas de teatro vazias. Corre o perigo nos próximos anos de se tornar marginalizada à medida que a indústria do lazer se profissionaliza cada vez mais e o jovens invistam menos tempo em fruir de um bem cultural. $O$ círculo de genuínos amantes das artes cênicas - os verdadeiros praticantes culturais - parece fechar-se e a cultura deve ser encontrada com mais frequência apenas em locais de entretenimento.

Daí também se constata que este tipo de habituée, pode estar em franca extinção, pois também não há políticas públicas voltadas para a educação cultural das crianças em idade escolar, onde, desde a tenra idade, elas podem desenvolver gosto pelos bens culturais para que isso se reverbere com o tempo. A chamada cultura da cultura não ecoa vigorosamente dentro do sistema de ensino público brasileiro. Quiçá do ensino privado, que prioriza, descaradamente, um colonialismo cultural.

Pode parecer para a cara leitora ou para o caro leitor, que esta Apresentação sirva, apenas, como um muro das lamentações, onde, 
encostados, nos limitamos a queixar-se de todas as agruras que este tema nos traz. Na verdade, serve esta introdução inicial, para despertar uma reflexão - ainda que superficial e sem qualquer desejo de resposta - sobre estas questões que, há muito, se instauraram e que parecem não ter fim por conta de um perverso ciclo vicioso entre o poder público e o privado e, caminhando junto, a ideia da arte como socializadora. Dito isso, continuemos.

Os equipamentos culturais são subaproveitados e a criação de novos deles, figuram sempre em planos de governo nos diversos municípios brasileiros. Tem-se uma visão mais econômica sobre isso do que uma visão artística: os bens públicos culturais têm impacto sobre a região onde são edificados e alteram os valores das propriedades no entorno. Construir um teatro ou um museu torna os bairros mais atraentes, torna melhores os lugares para morar e atrair cidadãs e cidadãos que pagam impostos locais mais altos e aumentam os preços dos terrenos e das casas. Já se têm, inclusive, estudos em economia cultural analisando os efeitos destas ações nas atividades e preços dos locais que orbitam em volta destes equipamentos.

Teixeira Coelho (2015) inclusive, questiona a justificativa para a existência de equipamentos culturais, se são de fato necessários, se de fato faltam ou se a recomendação de mais equipamentos culturais não seria, em alguma medida, uma questão da antiga política cultural. Por fim ainda pergunta se não teria a política cultural de alterar-se como a cultura se altera?

Precisamos mesmo de mais equipamentos culturais ou precisamos ressignificar o que já temos? A cultura não estaria à frente, anos luz, das políticas culturais atualmente existentes? A política cultural seria vista pela nova dinâmica cultural contemporânea como cringe, tal qual a "Geração Z" enxerga os "Millennials"?

Coelho questiona este novo sistema de produção cultural a partir de uma pergunta aparentemente simplificada, mas que impacta diretamente no resultado da distribuição de um produto de cultura:

"Que importa se um filme ou livro ou pintura são correta ou adequadamente usados ou consumidos em seu conteúdo, que importa se tem o conteúdo politicamente correto se, do ponto de vista da sociedade comunicativa, o que promove o novo sistema de produção cultural, com seus novos inputs - primeiro eletrônico 
depois digitais - é a fragmentação do público - que aparece agora como se colocado num túnel de aceleração de partículas a exemplo do Grande Colisor de Hádrons, perto de Genebra, e transformando numa miríade de entidades discretas, que fora das salas de espetáculo e da íntima sala de estar, nem sequer esbarram umas nas outras?" (COELHO, 2015)

Para o produtor cultural, ainda mais agora na pandemia, até então acostumado a trabalhar com um perfil de público relativamente definido e homogêneo, utilizando-se de equipamentos culturais para a exibição ou apresentação de sua obra, esta pergunta cai como uma bomba em seu planejamento de gestão, obrigando-o a repensar a forma de distribuição do seu produto no intuito de um maior alcance pelo menor custo.

Como o produtor cultural pode adaptar-se a esta realidade imposta pela tecnologia da informação onde o consumo imediato de um determinado produto cultural é servido de bandeja muitas vezes de forma mecânica e repetida, sem prejudicar o poder de renovação de um artista através da constante pesquisa de sua obra e de cercear a liberdade de criação do mesmo?

Precisam pensar e não é só nisso. Artistas e produtores brasileiros vivem um momento único. Deparam-se com públicos plurais que habitam a web e que acessam conteúdos culturais. Pensam nas comunidades e pessoas que não tem conexão de internet, atingidas pela barreira do acesso econômico. Pensam na interferência do governo na criação artística - uma clara censura - que se revela nos mais diversos decretos e pareceres de projetos culturais em todos os segmentos artísticos e que tolhem a liberdade artística. É triste e desanimador.

Como se não bastasse, novas demandas são incorporadas ao campo da cultura a cada dia, o que requer do artista e de um produtor, contato com diversas áreas de conhecimento como artes, administração, políticas públicas, educação, economia, comunicação, contabilidade, marketing, ciências sociais, etc., que contribuem para a complexificação e ampliação do campo.

E onde estão estas formações? Onde elas ficam acessíveis para todas e todos? Como pensar nestas questões em um país onde a disciplina de produção e/ou gestão cultural não aparece como obrigatória em quase todos 
os cursos de graduação em Artes Cênicas nas diversas Universidades públicas e privadas? Como entender a dinâmica das etapas de produção de um projeto cultural se não há qualquer amparo governamental para isso?

Mas sabemos a importância e o valor que produtores e produtoras de todas as regiões do Brasil têm. A profissionalização da cultura e as novas dinâmicas culturais contemporâneas, faz com que estes desempenhem cada vez mais um papel estratégico na interface das políticas públicas com a sociedade.

A produção e seus agentes culturais movimentam o processo cultural, criam projetos e dão forma e concretude às diversas iniciativas artísticas, numa interface direta e permanente com a sociedade, artistas e poderes instituídos. Desse profissional, se esperam múltiplas competências e responsabilidades.

Ao apresentar o perfil do gestor cultural, José Marcio Barros destaca alguns atributos desejáveis: “...mediador entre a dimensão subjetiva e sensível da cultura e os seus desdobramentos e interfaces... antes de ser um especialista em conhecimentos e práticas exclusivas e excludentes, é uma espécie de roteador de informações alternativas e possibilidades dinâmicas de construção de cenários prováveis, mas também de cenários utópicos... 0 gestor de hoje é um profissional da complexidade da cultura" (2008, p. $111 \mathrm{e}$ 112). A produção cultural, tal qual ela precisa ser vista hoje, nos convida a buscar mais informação e conhecimento teórico e prático sobre o produzir, com ou sem subsídio, para pequenos e grandes centros, para todo e qualquer modo ou meio de produção, sem desconsiderar a palavra produto, por mais que esta soe estranha quando colocada com a palavra cultura: produto cultural. É preciso ver a arte não só como resultado artístico, mas também como um produto final a ser oferecido aos diversos públicos nas mais diferentes áreas.

Outro ponto importante é a perda de públicos nos pequenos centros. Cidades provinciais do Brasil se deparam com um público jovem mais instruído migrando para cidades maiores, ficando estes lugares sem seu público em potencial e assim, encontram mais dificuldades ainda (além da falta de verba e infraestrutura) para fomentar a cultura na sua região. 
Os investimentos, ainda que em números pífios, concentram-se nos grandes centros e, em sua maioria, nas regiões Sudeste e Sul do país. E nestes lugares, como não há incentivo suficiente para o fomento das produções, há um vício por parte de alguns grupos ou coletivos artísticos em depender de subsídios culturais para a continuidade de suas criações. No entanto, não há oportunidades iguais para os recém-chegados ao mercado para competir de igual para igual com os grupos mais conhecidos que figuram constantemente nas listas de aprovados destes editais.

E por falar em editais, o que dizer sobre o dirigismo cultural, cada vez mais presente, principalmente da Lei Federal de Incentivo à Cultura (nome atual da antiga Lei Rouanet)? Ele vai contra qualquer princípio de estímulo e financiamento a diversidade cultural.

Ana de Hollanda, em entrevista a Carta Capital ${ }^{4}$, afirma que "Bolsonaro 5 impôs uma cartilha de governo moralista, que é misógina, homofóbica e racista. A cultura é a expressão mais espontânea do pensamento de um povo. Eles retratam o que estão vendo, a visão deles. A liberdade de criação é fundamental. O dirigismo cultural e a censura são opostos à criação artística".

Estas ações dificultam ainda mais a cadeia produtiva da cultura, ainda mais em um momento tão complicado com a pandemia da COVID19, que praticamente suspendeu todas as atividades artísticas do país.

O pesquisador chileno José Joaquín Brunner faz uma interessante análise das possíveis formas de interferência cultural em um ambiente democrático.

[...] as políticas culturais democráticas são - em um sentido mais geral - políticas formais. Buscam ajustes institucionais mais do que aplicar conteúdos cognitivos à sociedade. Buscam criar estruturas de oportunidades (mercados, sistemas de seleção, pluralidade de ofertas, variedade) e, ao mesmo tempo, impedir (mediante compensações, procedimentos, formas de controle, medidas de competição, abertura de bloqueios, etc.) que essas estruturas de oportunidades sejam objetos de social closure, de isolamento ideológico ou de qualquer forma de manipulação monopólica. (BRUNNER, 1987, p. 198)

\footnotetext{
${ }^{4}$ Carta Capital - https://www.cartacapital.com.br/cultura/ana-de-hollanda-o-dirigismo culturale-oposto-a-criacao-artistica/- Acesso em 22/07/2021.

${ }_{5}^{5}$ Presidente da República Jair Messias Bolsonaro, empossado em 01/01/2019, atual (des)governante do país.
} 
Ainda segundo Brunner (1987, 1988), tais ajustes institucionais deveriam intervir apenas nos níveis organizacionais do campo cultural, os circuitos culturais, que abarcam as fases de produção, transmissão e consumo dos bens culturais e cuja matriz básica é a combinação típica entre agentes (produtores profissionais, empresas privadas, agências públicas e associações voluntárias); instâncias institucionais de organização (administração pública, mercado e comunidade); meios de produção (sobre os quais incidem a base tecnológica, propriedade de meios e organização de agentes e meios); canais de comunicação (relativos ao condicionamento tecnológico e o acesso de agentes e públicos); e públicos. Desse modo, restaria assegurada uma estrutura institucional que garantiria formalmente aos indivíduos a oportunidade de aderir ao modelo ou de expressar os próprios valores culturais.

Para finalizar, ressalta-se a importância desta edição como um território amplo e significativo de reflexão, com interessantes orientações para teorizações e processos que possibilitem alguma estabilidade/segurança nas ações que estimulam a continuidade da produção em um trânsito evolutivo. Aqui, não se tem um objeto de estudo e sim uma situação de estudo. Aqui se apresenta a importância de narrar, contar uma relação artística e dar à produção um protagonismo necessário para a difusão das artes no Brasil.

Mais do que nunca, é fundamental falar sobre produção, pensar novos modos de viabilização, compartilhar experiências e descobrir oportunidades que antes pareciam distantes.

\section{Referências Bibliográficas}

BARROS, José Marcio. II. OLIVEIRA JÚNIOR, José. Pensar e agir com a cultura: desafios da gestão cultural. Belo Horizonte; Observatório da Diversidade Cultural, 2011, pg. 111-112.

BRUNNER, José Joaquín. Un espejo trizado: ensayos sobre cultura y políticas culturales. Santiago de Chile: FLACSO, 1988. 
BRUNNER, José Joaquín. Políticas culturales y democracia: hacia uma teoría de las oportunidades. In: GARCIA CANCLINI, Néstor (Org.) Políticas Culturales en América Latina. Buenos Aires: Grijalbo, 1987.pg. 13-59.

COELHO, Teixeira. Com o cérebro na mão: no século que gosta de si mesmo - 1 ed.- Itaú Cultural, São Paulo, 2015, pg. 25. 